\title{
THE GENERAL PRACTITIONER AND PREVENTIVE CARE
}

\author{
E. V. KUENSSBERG \\ M.B., Ch.B. \\ General Practitioner, Edinburgh
}

Although the obvious aim of one's personal effort must be to cure, yet to prevent can be a far.greater achievement and does give untold professional satisfaction. Unfortunately the amount of lip service paid to prevention is terrifying and, indeed, the impression is gained from our hospital colleagues not only that they have to work so hard, but also they have to cover up for our mistakes, all because general practitioners fail to prevent so much morbidity.

The pre-symptomatic detection of cervical carcinoma affords a good example of preventive care that should be attempted. Here everything is most favourable for early detection. The site of the possible pathological process is readily accessible, except in the unmarried, where the risk is much smaller. It is accessible not only to palpation, but also to inspection, and by the Ayre spatula technique we have an extremely simple method of taking scrapings for cytological diagnosis. When it is considered that a positive result

The Family Doctor Takes a Smear

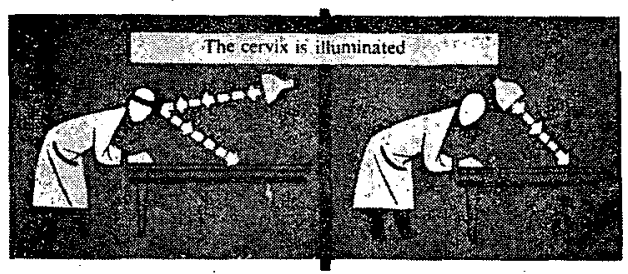

with light reflected from a head mirror or with an anglepoise lamp

And inspected.

Cells are obtained

by simple rotation of the Ayre

spatula on the cervix, are

smeared on a glass slide. and

are fixed with a solution of

absolute alcohol.
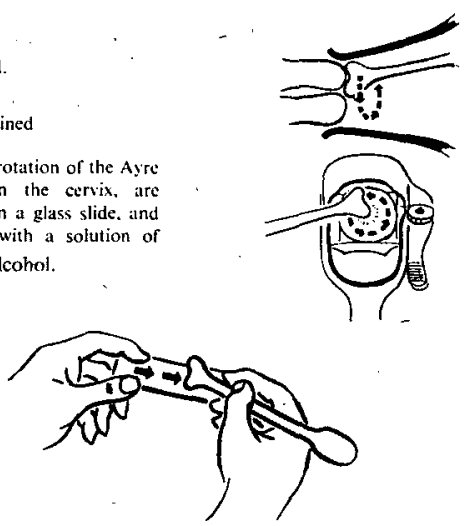

The slide is sent to a evlological diagnostic servict.

If the cytological report is positive. or doubsful, the patient is referred to a sneciallist.

Fig. 1 
may identify cancer some ten years before it would otherwise be detected clinically, it is amazing that so little has been achieved. Although the training of a cytologist may take some six months, the technique is still not routine in many areas even after fifteen years of a National Health Service.

The technique is illustrated in Fig. 1, and the main problem for the general practitioner is adequate illumination. Equipment need not be elaborate. Even the Ayre spatula is not absolutely necessary. A throat or vaginal swab, an ice-lolly stick, a wooden tongue depresser, are all adequate substitutes.

Inspection of the cervix routinely, quite apart from taking a smear, also plays a part in the prevention of frank disease. In the course of 100 consecutive cervical smears, I saw four symptomless polypi protruding through or originating from the cervix; these might have caused some misery later and they would not have been detected by the examining finger.

The time required for taking a smear varies from 30 to 90 seconds, and if you so organise your practice premises and ancillary staff (nurse-receptionist, or somebody conversant with simple procedures, somebody to complete the form, label the specimen and despatch it), then it can literally be done in a twinkling.

Cytological Report on 1,000 Cervical Smears

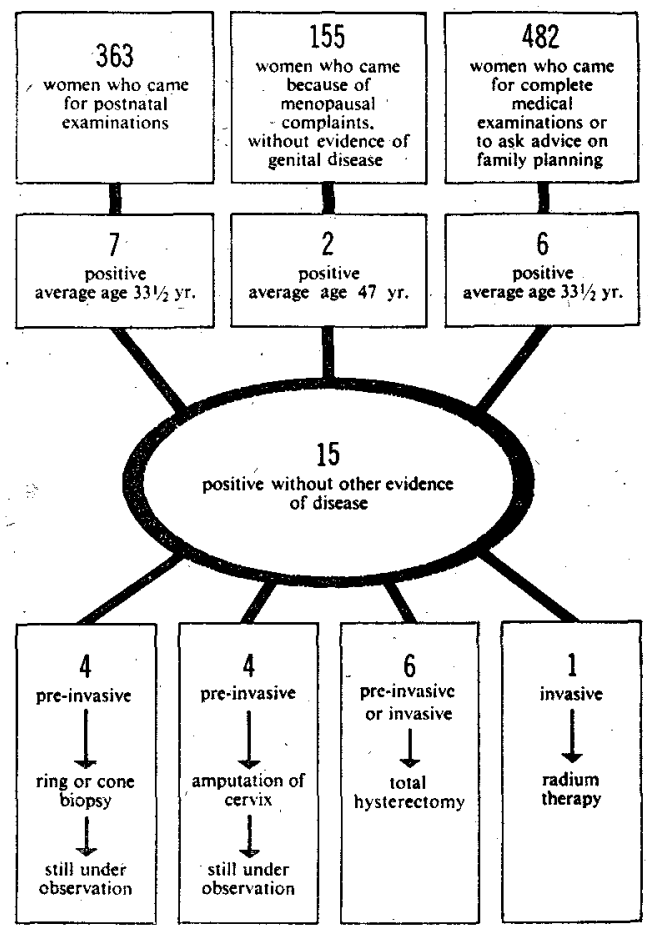

Fig. 2

These figures come from the College of General Practitioners' survey in the South East Scotland Faculty, published as long ago as 1958 . It will be noted that out of the 1,000 
women, 2 groups produced the highest incidence:- the post-natal group, and the group of women who came either because of family planning advice or required pelvic examination for the exclusion of a differential diagnosis although having, however, no frank gynaecological complaints. The average age for those with a pre-invasive cervical carcinoma in these 2 high risk groups was $33 \frac{1}{2}$ years. 10 years younger than the age of maximum incidence of carcinoma of cervix.

These facts are broadly supported by the results of the Aberdeen hospital-based survey reported by McGregor and Baird (1963). The slightly higher figures for positive smears in the general practitioners' series in the 1958 survey may be related to the larger proportion of women seen in the lower socio-economic groups, as the Aberdeen one clearly demonstrates the higher incidence of positive smears in the lower socio-economic groups, who are less easy to persuade to attend.

What does this mean in terms of actual patients? The following table shows the results of cervical smears taken during ordinary consulting hours from three groups of patients in our partnership.

Table 1.

Analysis of Cervical smears in an Edinburgh N.H.S. General Practice Prevalence of unsuspected positives according to reason for taking sniear

\begin{tabular}{|c|c|c|c|}
\hline & $\begin{array}{l}\text { Number of } \\
\text { Smears } \\
\text { Examined }\end{array}$ & $\begin{array}{l}\text { Number } \\
+ \text { ve }\end{array}$ & $\begin{array}{l}\text { Unsuspected } \\
\text { Positives } \\
\text { Rate per } 1000\end{array}$ \\
\hline Post-natal Examination & 225 & 6 & 26.7 \\
\hline Menopausal Examination & 106 & 2 & 18.9 \\
\hline Other Reasons & 259 & 3 & 11.6 \\
\hline TOTAL & 590 & 11 & 18.6 \\
\hline
\end{tabular}

Seven to eight years later, in 1964, all 11 patients with a positive smear are still alive and well: 2 had a further pregnancy before hysterectomy, when the presence of early malignancy was confirmed in the removed cervix. In contrast during the time taken to collect these 11 patients, 4 others in the same group, presenting with clinical symptoms of cervical carcinoma, had this diagnosis confirmed. All these four women underwent extensive surgery and X-ray therapy and subsequently died, the last death occurring in 1961.

That screening cytology of the female population can be successful has now been demonstrated by Boyce et al. in British Columbia, where a thorough programme involving. nearly all general practitioners, achieved a significant reduction in the incidence of invasive carcinoma in 5 years (from 28.4 cases per 1,000 to 19.7 cases).

However, to rush at once into a national screening programme, without adequately trained personnel, would only bring cytology into disrepute. But it seems essential that we should begin at once to take smears of the high risk groups. 30 years and above seems to be a more critical age, particularly it associated with greater parity. The age group 35-40 yields as high a result of unsuspected positives as 32.5 per thousand, in contrast to the average of $10-15$ per thousand over all age groups.

A more controversial problem is the early detection of patients with glycosuria, especially if their blood sugar curve shows a pre-diabetic pattern. Can we, in fact, alter 
the course of diabetes? Can we, in fact, prevent frank diabetes occurring? Whilst these questions are being answered by special investigations and surveys, it seems obvious that meantime, we must test for sugar, especially in the special high risk groups; the over 50 's, those who are, or have been obese; women who have borne more than six children, particularly those who produce babies weighing over 10 pounds, or who have successive children of increasing birth weight; those who are close relatives of known diabetics, and finally, those patients with cardio-vascular, cerebrovascular, peripheral vascular defects, gangrene, ulcerative chronic sepsis of skin, women with vulvitis and men with balanitis. Population surveys in Perth and other places have clearly indicated the value of the "do-it-yourself" method, where the patient is issued with Clinistix and the appropriate instructions.

The prevention of chronic urinary tract infection is also important. The adequacy of treatment of a single episode of urinary tract infection must be checked by such bacteriological examination of the urine as the "visible count" or triphenyl tetrazolium chloride (T.T.C.) test for the presence of pyogenic organisms. The special high risk groups might include children with urinary infection, child-bearing women, and any other patients with a second or third attack of urinary infection.

For the sake of completeness, other preventive procedures the general practitioner is traditionally engaged in are:-

(1) antenatal care,

(2) assessment and screening of the newborn for detection of the "At Risk" group (specific examples: the hip joint click in the detection of congenital dislocation of hip joint; the Phenystix test for phenylketonuria),

(3) infant care,

(4) the periodic follow-up of the " over $65 \mathrm{~s}$ ".

Patients in groups 2, 3 and 4 , depend on someone else to bring them to the attention of the practitioner, and the usual self-reporting of patients is therefore not applicable. This fact is important in planning the preventive work of the general practitioner, and so clearly requires him to work closely with members of the Local Health Authority.

A slightly different aspect of prevention, and one almost peculiar to general practice, is seen in the family doctor's management of established disease in certain patients whom he knows from past experience to be particularly liable to run into further trouble. Examples are afforded by the temporary addition of anticonvulsants to the regime for the fevered child liable to febrile convulsions; the use of a broad spectrum antibiotic for the "wheezy child" with a cold; the additional visiting for the inadequate patient under stress, just to name a few. In this category might also be included patients who require special long-term surveillance because of previous treatment: the patient with partical gastrectomy for anaemia or evidence of vitamin $B_{12}$ deficiency, those on anticonvulsants for macrocytic anaemia, the patient with thyroidectomy for myxoedema or tetany.

The smoker and the bronchitic are also high risk groups requiring special treatment and presymptomatic diagnostic procedures. The chronic bronchitic whose progress to cor pulmonale might be slowed by adequate treatment of exacerbations is a further example.

There is another man-made hazard not yet fully understood, which will require special alertness from the general practitioner; the young women taking the "Pincus." pill in one form or another, as she is exposing herself for long periods; with our medical 
connivance to only partially grasped consequences.

It is often claimed that because of his knowledge of his patient's family and the morbid processes to which they may be prone, the general practitioner has yet another contribution to make to prevention. The example of the family at risk to rheumatic fever is demonstrated in Table 2.

Table 2.

Children of Parents with a Clinical History of Rheumatic Fever

\begin{tabular}{c|c|c|c}
\hline & $\begin{array}{c}\text { Total number } \\
\text { in } \\
\text { practice }\end{array}$ & $\begin{array}{c}\text { Actual number } \\
\text { of offspring with } \\
\text { rheumatic fever }\end{array}$ & $\begin{array}{c}\text { Expected number } \\
\text { based on age/sex } \\
\text { specific rates in } \\
\text { practice }\end{array}$ \\
\hline Sons aged 5-39 years & 136 & $3\left(2^{*}\right)$ & 0.50 \\
\hline Daughters aged 5-39 years & 136 & $7\left(4^{*}\right)$ & 0.75 \\
\hline TOTAL & 272 & $10\left(6^{*}\right)$ & 1.25 \\
\hline
\end{tabular}

*Rheumatic heart involvement

This table clearly shows the greater prevalence of rheumatic fever, including cardiac involvement; in children of a parent with the history of rheumatic fever, in our partnership of seven in Edinburgh. Adequate penicillin therapy should thus be seriously considered for patients in this group with even a minor throat infection.

Our group practice records provide a further example in the field of family morbidity. There are 190 patients suffering from various forms of cancer at present (1st. July, 1964) alive in our practice. They have a total of 324 living children of whom 28 (10 males and 18 females) are over 35 years of age. 3 of the 18 women also have cancer, each arising in the same site as in the mother. 2 daughters with carcinoma of cervix were detected in the pre-invasive stage by cytology, and one daughter had her breast cancer revealed by mammography. Such figures are too small to be statistically significant, although they suggest that the screening of daughters of mothers with cancer might be worthwhile. At any rate, such a daughter's fear of cancer should never be shrugged off.

There are other diseases, notorious for their familial occurrence, and the family doctor may be well placed to modify their effects -if not to prevent their appearance-in closer relatives of those already afflicted. The prevention of blindness, by an awareness of the possibility of glaucoma in siblings of those having this disease, affords one example. Or, in the case of Huntington's chorea, the disastrous social effects may be modified by being alive to this possible diagnosis at a very early stage.

Linked with this is the question of the role of the family doctor in genetic counselling. He may have a part to play in the prevention of epilepsy, haemophilia and related diseases, mongolism, haemolytic disease of the newborn, and so on, although his role will often be merely to re-inforce or to interpret the advice of those more expert in this field.

How is all this to be achieved by the general practitioner to-day? This mammoth. task of keeping high risk groups of patients under surveillance, screening them whenever the opportunity arises, can only be attempted if the practitioner has all the help he needs: nurses, ancillary social workers, health visitors, and not least of all secretarial assistance. The National Health Service (and the Armed Forces Medical Service) has provided one essential for pre-symptomatic diagnosis and control in the fact that there 
is now one medical record for nearly every member of the population: Here is one of the greatest tools for precise scientific follow-up, for proper record keeping and all that flows from it. Accurate documentation is increasingly important as more and more precise measurements become available, but good record keeping must be supported by ancillary secretarial help, and mechanical devices such as modern methods of visible indexing and colour tagging. Only then, can we hope to keep track of the "high-risk group of patients" not only as individuals, but as families.

In summarising it must, however, be emphasised that although regular and effective screening of the community may be theoretically ideal, there is a real danger of forgetting the amount of illness that is, and can be prevented by conventional methods, particularly by paying selective attention to the high risk groups.

Having ranged widely and broadly over many aspects of general practice in relation to early diagnosis and prevention, I am convinced that:-

(1) we must create conditions in our N.H.S. practices where accurate recordkeeping is a basic fact,

(2) we must identify high risk groups of patients and submit them to special screening procedure or investigation, or surveillance, whichever is appropriate,

(3) all the help for it must be made available to the general practitioner.

\section{REFERENCES}

Knox, J. D. E. and Kuenssberg, E. V. (1964). "Rheumatic and Other Locomotor Diseases". Med. Wld. (Lond.). 100, 456.

KuensSBERG, E. V. (1964). " Recording of Morbidity of Families ". J. Coll. Gen. Practit. 7, 410.

South East Scotland Faculty of the College of General Practitioners. (1958). "Cytological Screening of. 1000 Women for Cervical Cancer". Lancet. 11, 895.

MacGregor, D. E. and BArRD, Sir Dugald. (1963). "Detection of Cervical Carcinoma in the General Population". Brit. med.J. 1, 1631.

\section{Royal College of Surgeons of England}

Mr. Hedley John Barnard Atkins, Professor of Surgery in the University of London and Director of the Department of Surgery, Guys Hospital, has been elected President of the Royal College of Surgeons of England. Son of the late Colonel Sir John Atkins, who served in the South African war and was Physician in Ordinary to our first Colonelin-Chief, the Duke of Connaught, Professor Atkins is no stranger to our Corps. He held a commission in the R.A.M.C. from 1941-1945 and served in North Africa and Italy in the rank of Lieut. Colonel and was mentioned in despatches. He is a frequent and welcome visitor to the Queen Alexandra Military Hospital, regularly bringing his students for surgical teaching rounds. 